\section{Pulmonary Metastases in Wilms' Tumour: Treatment and Prognosis*}

Wilms' tumour, or nephroblastoma, accounts for approximately $5 \%$ of all malignant disease in childhood, according to figures from the Manchester Children's Tumour Registry (Marsden and Steward, 1968). Its mode of spread is usually direct to adjacent structures, and via lymph and blood-stream to lymph nodes, liver, and lungs. After the initial surgical excision of the tumour together with any affected adjacent structures and lymph nodes, the commonest site for recurrence is in the lungs. In many children the recurrence is confined to the lungs, and it is the management and prognosis of this particular group of children that we wish to discuss.

On reviewing the larger series of children with Wilms' tumour in the literature, small numbers of patients have been described where pulmonary metastases have been successfully treated (Swenson, 1969; Snyder, Hastings, and Pollock, 1969; Johnson, Maceira, and Koop, 1967). A variety of methods has been employed; radiotherapy, surgery, chemotherapy, and various combinations of these. However, in a recent major textbook of paediatric urology the comment is made, 'late recurrences in the lungs have been treated . . . but with relatively little success' (Williams, 1968). We wish to describe our experiences in Liverpool to illustrate that such a view is too gloomy.

At Alder Hey Hospital and the Royal Liverpool Children's Hospital over a 21-year period from 1948-1968, 63 children with Wilms' tumour were seen. This group is believed to be all but 2 of the cases that occurred in the Liverpool area in this period. Of these 63 children, 16 patients, that is 1 in 4 , were treated at some stage of their illness for metastases confined to the lungs. The ages of these 16 children ranged from 11 months to 11 years, and 14 of the 16 were aged 5 years or less: 9 were girls and 7 boys. 14 of the 16 children had initial surgical excision of their abdominal tumour via the transabdominal approach, with early ligation of the renal vessels, followed by radiotherapy to their

*Communication given to the Annual Meeting of the British Paediatric Association, Scarborough, 1970. abdomen. The radiated field was usually the hemi-abdomen but crossing the spine to prevent asymmetrical growth. 2 children had radiotherapy before surgical excision.

\section{Results}

In one child pulmonary secondaries were present at the time of diagnosis, in 11 they occurred within 6 months of diagnosis, and in all but one case metastases developed within one year. The 16 children had their lung recurrences treated in two principal ways.

(1) The larger group of 11 children received radiotherapy to their lung fields (Table I). The policy was to irradiate both fields regardless of the site(s) of the metastases. High voltage machines were used and total doses ranged from 1200-3400 roentgen (usually about 2500 roentgen). In addition actinomycin $\mathrm{D}$ was given in 4 children treated later in the series.

TABLE I

Radiotherapy Group

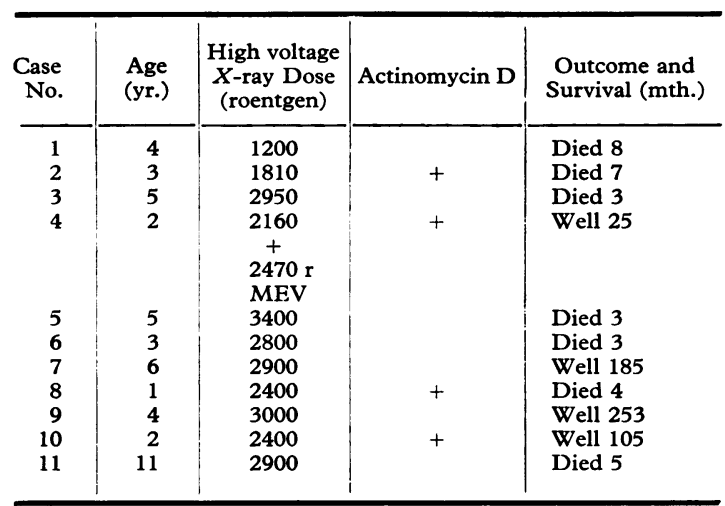

The results of treatment in these 11 children were as follows: 4 are alive and well $2,9,15$, and 21 years later; 1 of these children had a malignant effusion accompanying her pulmonary metastases, and another child had a mediastinal secondary which was irradiated; it recurred 6 months later, was irradiated again, and she is now well, over 2 years later. 7 children died; of these 3 died within 3 months of completing their radiotherapy and at 
post-mortem examination there was no evidence of malignancy but only of fibrosis and infection. These 3 children received 2950,2800, and 3400 roentgen, respectively, and none of them was given actinomycin D which is known to potentiate the effects of radiotherapy on the lungs. They were all treated early in the series. The other 4 children who died all developed further lung metastases and died $4,5,7$, and 8 months later.

(2) In a smaller group of 5 children surgical excision of the pulmonary metastases was performed (Table II). 3 of these children had a solitary pulmonary metastasis excised, but in the other 2 metastases were present in more than one lobe. In the first of these, wedge resections were performed in the right upper and right lower lobes at the same operation, and in the second child a wedge resection of a metastasis in the left upper lobe was followed a week later by removal of the right lower lobe which contained a further metastasis. Of this group, 3 children received actinomycin $\mathrm{D}$, in 2 cases, a single course at the time of operation, and in the other case, 4 courses over a period of one year starting at the time of operation. 3 of these 5 children are alive and free of disease 19 months, 4 years, and 11 years later. The 2 children who died survived 13 and 15 months from the time of their lung resection, and both developed further lung metastases.

TABLE II

Surgical Group

\begin{tabular}{c|c|c|c|l}
\hline $\begin{array}{c}\text { Case } \\
\text { No. }\end{array}$ & Age & Excision & Actinomycin D & $\begin{array}{l}\text { Outcome (mth.) } \\
\text { Survival }\end{array}$ \\
\hline 12 & 11 mth. & + & + & Well 19 \\
13 & 3 yr. & + & & Well 137 \\
14 & 15 mth. & + & + & Died 13 \\
15 & 22 mth. & + & + & Died 15 \\
16 & $4 \frac{1}{2}$ yr. & + & + & Well 54 \\
\hline
\end{tabular}

Since 1960 in addition to either operation or radiotherapy we have given actinomycin $D$. At first this drug was given either at the time or shortly after the initial therapy in a single course, but in the last 2 patients repeated courses at 4-monthly intervals over a year have been given. There is a considerable amount of published material confirming the usefulness of this drug, and in addition there is now good evidence from the American Cancer Study Group A among others that repeated courses are more effective than a single course (Wolff et al., 1968). We use $15 \mu \mathrm{g} . / \mathrm{kg}$. per day for 5 or 6 days in each course and have had very little in the way of side-effects.
Combining the results in these two groups of patients, 7 of the 16 children are alive, well, and show no evidence of their disease from 19 months to 21 years later (Table III). A further 3 children died probably as a result of their treatment and at necropsy showed no evidence of malignancy. These results emphasize the important of an energetic approach to this problem, with the likelihood of 1 in 2 children surviving as a result. With modern radiotherapeutic techniques using megavoltage machines, and with the realization that actinomycin D potentiates the effects of $x$-rays on the lungs, radiation fibrosis of the lungs should be avoided.

TABLE III

Combined Results

\begin{tabular}{|c|c|c|c|}
\hline Treatment & $\begin{array}{l}\text { No. of } \\
\text { Patients }\end{array}$ & Died & Alive \\
\hline 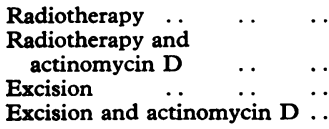 & $\begin{array}{l}7 \\
4 \\
2 \\
3\end{array}$ & $\begin{array}{l}5 \\
2 \\
1 \\
1\end{array}$ & $\begin{array}{l}2 \\
2 \\
1 \\
2\end{array}$ \\
\hline & 16 & 9 & 7 \\
\hline
\end{tabular}

\section{Conclusions}

(1) In a representative group of children with Wilms' tumour 1 in 4 developed metastases confined to the lungs at some stage of their illness.

(2) As 12 out of 16 children developed lung secondaries within 6 months of diagnosis, careful follow-up of children with Wilms' tumour, especially in the early stages, is vital. It is our practice to do chest $x$-rays at least at 4-weekly intervals throughout the first year as most metastases are asymptomatic. Any suspicious shadow should lead to tomography.

(3) If lung metastases are found and there is no other evidence of recurrence, a vigorous attempt should be made to cure the child for about half the children may be cured.

(4) Surgical removal of pulmonary metastases should only be considered if one or two isolated deposits are found, confirmed by tomography, and which are not adjacent to the mediastinum or do not involve the pleura. Where deposits are multiple, adjacent to the mediastinum, or involving the pleura, radiotherapy is the treatment of choice.

(5) In the light of present knowledge actinomycin $\mathrm{D}$ should be given in addition to surgical or radiation treatment. This should be given in repeated courses 
over a period of at least 12 months. It may well be that other chemotherapeutic reagents should be considered as well.

\section{Summary}

Of 63 children treated for Wilms' tumour during the past 21 years, 16 developed metastases confined to the lung, shortly after the initial treatment. Treatment by operation, radiotherapy, and chemotherapy or a combination of these methods can give reasonably good results in children suffering from pulmonary metastases secondary to Wilms' tumour. 7 of the 16 patients are alive and well $1 \frac{1}{2}$ to 21 years after they developed clinically recognizable pulmonary lesions.

We would like to thank Dr. Dorothy Mainwaring and Dr. W. B. Dawson for their help and advice in the preparation of this paper.

\section{REFBRENCES}

Johnson, D. G., Maceira, F., and Koop, C. E. (1967). Wilms' tumour treated with actinomycin $D$. The relationship of age and extent of disease to survival. Fournal of Pediatric Surgery, $2,13$.

Marsden, H. B. and Steward, J. K. (1968). Tumors in Children. p. 225. (Recent Results in Cancer Research, 13), Springer,Berlin .

Snyder, W. H., Jr., Hastings, T. N., and Pollock, W. F. (1969). Retroperitoneal tumors. In Pediatric Surgery, vol 2. p. 1020 Ed. by W. T. Mustard, M. M. Ravitch, W. H. Snyder, Jr., K. J. Welch, and C. D. Benson. Year Book Medical Publishers, Chicago.

Swenson, O. (1969). Pediatric Surgery. Appleton Century Crofts, New York.

Williams, D. I. (1968). Paediatric Urology. Butterworths, London.

Wolff, J. A., Krivit, W., Newton, W. A., Jr., and D'Angio, G. J. (1968). Single versus multiple dose actinomycin therapy of Wilms's tumor. New England fournal of Medicine, 279, 290.

J. MARTIN and P. P. RickHAM

Alder Hey Children's Hospital, Liverpool 12

\section{Sputum Viscosity and Pulmonary Function in Cystic Fibrosis}

The development of the pulmonary lesions in cystic fibrosis (CF) has been attributed to obstruction of the airways by abnormally viscous mucus (Farber, 1944). We have examined the relation between sputum viscosity and pulmonary function in CF.

\section{Patients and Methods}

The patients studied (Table) were described in a previous publication (Feather and Russell, 1970a). Of a total of 30 patients with CF in the North-Eastern Hospital Region of Scotland, only the 5 described regularly produced sputum. During the period of study patients were in a clinically stable phase of their illness and their usual therapy remained unchanged.
TABLE

Details of Patients with Cystic Fibrosis

\begin{tabular}{|c|c|c|c|c|c|c|c|}
\hline \multicolumn{6}{|c|}{ Case No. } & \multirow{2}{*}{$\begin{array}{r}\text { Age } \\
(y r .)\end{array}$} & \multirow{2}{*}{$\begin{array}{l}\text { Sex } \\
\mathbf{M} \\
\mathbf{M} \\
\mathbf{F} \\
\mathbf{F} \\
\mathbf{M}\end{array}$} \\
\hline $\begin{array}{l}1 \\
2 \\
3 \\
4 \\
5\end{array}$ & 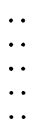 & $\begin{array}{c}\ldots \\
\ldots \\
\ldots \\
\ldots\end{array}$ & $\begin{array}{c}\ldots \\
\ldots \\
\ldots \\
\cdots\end{array}$ & $\begin{array}{l}\ldots \\
\cdots \\
\cdots \\
\cdots\end{array}$ & $\begin{array}{l}\cdots \\
\cdots \\
\cdots \\
\cdots\end{array}$ & & \\
\hline
\end{tabular}

The sputum specimens studied were expectorated spontaneously during the first hour after waking; no means of liquefying the sputum was used before expectorating the samples. Apparent viscosity at $900 \mathrm{sec}^{-1}$ of each sputum sample was measured within two hours of expectoration on a cone and plate viscometer, as described elsewhere (Feather and Russell, 1970a). A significant correlation has been shown between this and other measures of sputum viscosity in these patients (Feather and Russell, 1970b).

The forced expiratory volume in one second $\left(\mathrm{FEV}_{1 \cdot 0}\right)$ and forced vital capacity (FVC) were measured by means of a dry spirometer. ${ }^{\star}$ On each occasion the best of three measurements taken before, and the best of three taken after the inhalation of isoprenaline were recorded. To avoid the inclusion of any reversible airways obstruction (present at times in all the patients studied) the 'over-all best' (i.e. before or after the inhalation of isoprenaline) FEV $_{1.0}$ and FVC were recorded. All volumes were converted to BTPS and expressed as a percentage of the predicted value. Predicted values were obtained from the data of Strang (1959) supplemented for the FVC of Case 3 by those of Lunn (1965).

Results were obtained during the control period for the trial of tolazoline, previously reported (Feather and Russell, 1970a). Sputum viscosity was measured on the same day and as close in time as possible to lung volume measurements. Measurements were made on days 4 and 7 of each week. The data for the Fig. were obtained during week 1 .

To examine the relation between day-to-day changes in sputum viscosity and changes in pulmonary function, these measurements made on the same day during the period of observation were compared. Because tolazoline had no demonstrable effect on either sputum viscosity or respiratory function, results obtained during the four weeks of observation were pooled.

\section{Results}

The Fig. shows the relation between $\mathrm{FEV}_{1.0}$, FVC, and the viscosity of sputum in individual patients. The correlation coefficients for viscosity with FEV 1.0 $_{0}$ and FVC were significant and negative (for $\mathrm{FEV}_{1.0}, \mathrm{r}=-0.92, \mathrm{p}<0.05$; for FVC $\mathrm{r}=$ $-0.903, p<0.05)$. No relation was shown be-

^Vitalograph, Vitalograph Ltd., Buckingham, England. 